\title{
BULLYING PADA ANAK USIA DINI
}

\author{
Andini Dwi Arumsari, M.Psi, Psikolog \\ Dosen Program Studi PG PAUD \\ Fakultas Keguruan dan Ilmu Pendidikan \\ Universitas Narotama Surabaya \\ Andini.dwi@narotama.ac.id
}

\begin{abstract}
Abstrak
Pendidikan Anak Usia dini adalah pendidikan yang diberikan pada masa emasnya yaitu pada usia 0-6 tahun. Di masa itu, anak juga seringkali mengalami kesulitan di masa tumbuh kembangnya. Permasalahan yang biasanya muncul pada perkembangan sosial emosinal anak dapat dilihat dengan adanya perilaku anak yang kurang tepat, baik di rumah maupun di sekolah, salah satunya adalah perilaku bullying. Bullying mulai muncul di TK. Anak yang diusia dininya terindikasi dan terlibat dalam perilaku bullying, berpotensi untuk menjadi pelaku kenakalan di usia remajanya, tindakan kekerasan, serta terjebak dalam tindakan kriminal. Perilaku bullying seringkali terjadi di sekolah yang kurang pengawasan dari guru, longgar dalam menerapkan aturan, serta pihak-pihak pemegang otoritas tidak memiliki sikap dan pandangan yang tegas terhadap bullying. Pengetahuan guru TK tentang bullying juga dirasakan masih terbatas. Peningkatan pengetahuan dan keterampilan guru dapat dilakukan dengan program psikoedukasi yang diberikan kepada guru mengenai perilaku bullying.
\end{abstract}

Keywords: anak usia dini, bullying, psikoedukasi, usia emas

\begin{abstract}
Early Childhood Education is the education given in its golden age at the age of 0-6 years. At that time, children also often have difficulty in the growth period. The problems that usually arise in the child's emotional social development can be seen by the inappropriate behavior of children, both at home and at school. One of them is bullying behavior. Bullying starts to appear in kindergarten. The child he was identified with and involved in bullying behaviors, has the potential to become a juvenile delinquent in his teens, violent acts, and trapped in criminal acts. Bullying behavior often occurs in schools that are less supervisory than teachers, loose in applying the rules, as well as the parties of authorities do not have a firm attitude and a firm view of bullying. Kindergarten teacher knowledge about bullying is also felt to be limited. Increased teacher knowledge and skills can be done with psychoeducation programs given to teachers regarding bullying behavior
\end{abstract}

Keywords: Early Childhood, Bullying, Psychoeducation, Golden Age 


\section{PENDAHULUAN}

Masa anak usia dini adalah masa emas (golden age), dimana pada masa itu anak diberikan stimulus yang tepat agar perkembangan kognitif, bahasa, motorik, dan sosial emosionalnya dapat berkembang secara maksimal. Masa emas anak usia dini adalah pada anak dalam kandungan hingga usia dini, yaitu 0-6 tahun. Pendidikan Anak Usia Dini (PAUD) adalah pendidikan yang diberikan pada anak usia $0-6$ tahun. PAUD menjadi pendidikan yang penting bagi anak. Hal ini berkaitan dengan masa pertumbuhan dan perkembagnan otak anak yang sudah mencapai $80 \%$ pada usia 6 tahun. Pada usia tersebut segala sesuatu yang diterima anak akan dapat memberikan bekas yang kuat dan tahan lama. Kesalahan mendidik anak akan memberkan efek negatif jangka panjang yang sulit diperbaiki (Khasanah, 2013).

Pada masa ini, anak-anak juga harus melalui berbagai macam kesulitan. Dalam masa perkembangannya, anak akan melalui beberapa fase dengan berbagai macam tingkat kesulitan dan permasalahan. Sehingga dengan mengetahui tugas perkembangan dari anak, konflik yang akan ditimbulkan dalam kehidupan sehari-hari dapat dicegah. Pada masa ini pun, anak-anak akan mengalami fase pengenalan dengan lingkungan sosialnya, mulai lingkungan keluarga, masyarakat, dan sekolahnya.

Munculnya permasalahan pada perkembangan sosial emosinal anak dapat dilihat dengan munculnya perilaku anak yang kurang tepat, baik di rumah maupu di sekolah. Misalnya memukul, mendorong, mencubit, mencakar, merusak barang orang lain, mengejek, mengancam, menjulurkan lidah, memanggil nama temannya dengan menggunakan julukan, dll. Salah satu kejadian yang sering dilakukan pada anak saat bermain adalah perilaku bullying, baik di lingkungan rumah maupun di sekolah. Perilaku bullying merupakan permasalahan sosial yang terjadi di sekolah yang ada di seluruh dunia (Smith, Cousin, \& Stewart, 2005).

Olweus (1993) mengungkapkan bahwa perilaku bullying terjadi mulai usia TK dan puncak permasalahannya pada sekolah menengah. Sekolah Taman Kanak-Kanak merupakan institusi yang sangat berperan penting dalam kedua hal tersebut di atas. Anak memperoleh pengetahuan dan pengalaman berharga berkaitan dengan pembentukan perilaku anti bullying melalui metode-metode pendidikan yang diimplementasikan oleh guru TK. Salah satu upaya dalam bidang pendidikan untuk mencegah maupun mengatasi masalah bullying sejak dini adalah dengan memberikan bimbingan kepada anak usia dini di lingkungan sekolah itu sendiri (Putri, 2016). Contoh perilaku bullying yang terjadi di TK X di kota Surabaya. Penelitian yang dilakukan oleh Putri (2016) menyatakan bahwa perilaku bullying terjadi di TK tersebut. Korban bullying adalah siswa bernama D. D selalu menjadi bahan ejekan oleh 
teman-teman sebayanya. Biasanya teman-temannya membully dia dengan sebutan cewek dekil, hitam, dan tangannya asin.

Beberapa penelitian menunjukkan bahwa anak laki-laki lebih memungkinkan untuk melakukan perilaku bullying dibandingkan anak-anak perempuan (Olweus, 1993; Smith \& Sharp 1994; dalam Rigby, 2003). Selain itu, kesempatan anak-anak perempuan lebih besar dibandingkan anak lak-laki untuk menjadi korban perilaku bullying (Cassidy, 2009). Penelitian di Australia yang diberikan kepada 38.000 anak-anak, menunjukkan bahwa sebanyak 22,1\% anak perempuan mengaku diganggu oleh anak laki-laki, dan sebanyak 3,4\% anak laki-laki mengaku diganggu oleh anak perempuan (Rigby, 2003). Hal tersebut menunjukkan bahwa anak laki-laki lebih banyak melakukan perilaku bullying dibandingkan anak perempuan. Biasanya anak laki-laki melakukan prilaku bullying secara fisik, sedangkan anak perempuan biasanya melakukan perilaku bullying dalam bentuk verbal, mental, maupun sosial.

\section{BULLYING}

Perilaku bullying sering diartikan sebagai bagian dari perilaku agresif. Bullying adalah pengulangan perilaku negatif (baik secara fisik, verbal maupun psikologis) yang ditujukan secara langsung kepada korban dan akan menyakiti korban (Olweus, 1997), dilakukan berulang-ulang dan sepanjang waktu, dan melibatkan adanya perbedaan kekuatan antara korban dan pelaku (Olweus, 2005). Menurut Robinson \& Maines (2008), bullying adalah sebuah perilaku sosial yang melibatkan beberapa anak, terjadi berulang kali, dilakukan untuk memenuhi kebutuhan anak yang berkuasa di lingkungan sosialnya, dan dapat menjadi bahaya bagi anak yang tidak punya kekuatan untuk menghentikannya. Bullying biasanya terjadi secara berkelanjutan dan dalam jangka waktu yang cukup lama, sehingga korban akan selalu merasa cemas dan terintimidasi. Bullying berbeda dengan perilaku agresif lain yang dilakukan hanya satu kali kesempatan dan dalam jangka waktu pendek.

Perilaku agresi tidak akan diidentifikasi sebagai perilaku bullying kecuali korban merasa takut yang berkelanjutan. Olweus (Safe School Centre, 1999) menyebutkan tiga kondisi utama yang membedakan perilaku bullying dengan bentuk perilaku agresif lainnya, yaitu kekuatan: anak-anak yang melakukan bullying mendapatkan kekuatannya melalui ukuran fisik serta status dalam kelompok sebayanya, dan dengan mendapatkan dukungan dari kelompok sebayanya, frekuensi: perilaku bullying bukan merupakan tindakan yang acak. Bullying selalu ditandai dengan adanya serangan yang terjadi dan dilakukan berulang-ulang, 
dan adanya niat untuk menyakiti: anak-anak yang melakukan bullying umumnya melakukan tindakan tersebut untuk membahayakan anak lain, baik secara fisik ataupun emosional.

Perilaku bullying dibagi menjadi dua kategori, bullying yang dilakukan secara langsung dan tidak langsung (Smith et.al, 2005). Bullying yang dilakukan secara langsung termasuk pada perilaku verbal dan non verbal. Perilaku verbal pada bullying seperti mengejek, berteriak, dll. Mengancam melalui telepon adalah bentuk baru dari bullying verbal (Porter, 2007). Perilaku non verbal pada bullying seperti memukul, menendang, dll. Bullying yang dilakukan secara tidak langsung lebih sulit untuk diobservasi, seperti menyebarkan gosip, mengucilkan seseorang dari kelompok mereka, dll. Bullying yang dilakukan secara tidak langsung akan sulit untuk dideteksi oleh pihak sekolah.

\section{YANG TERLIBAT DALAM PERISTIWA BULLYING}

Peristiwa bullying seringkali melibatkan pelaku, korban, dan pengamat. Sullivan (2000) mengatakan bahwa bullying melibatkan 3 hal: pelaku, korban, dan orang yang melihat perilaku bullying tersebut. Pelaku bullying adalah seseorang atau kelompok yang berperilaku sama dan mempunyai kebutuhan yang sama. Kebutuhan tersebut seperti kebutuhan melakukan sesuatu yang menyenangkan bagi pelaku, mendapatkan status sosial tertentu atau keuntungan materi, dan tidak memperdulikan kebutuhan dan hak orang lain (Robinson \& Maines, 2008). Anak-anak yang sering menjadi korban bullying (victim) adalah seseorang atau kelompok yang merasa disakiti oleh perilaku orang lain dan tidak mempunyai kekuatan, kemampuan, atau kemungkinan untuk melawan atau menghentikan perilaku yang menyakiti tersebut (Robinson \& Maines, 2008). Individu yang melihat perilaku bullying disebut dengan bystanders. Bystanders adalah seorang anak yang menjadi saksi perilaku bullying. Bystander biasanya melakukan sesuatu tetapi mungkin juga mereka tidak melakukan apapun untuk menghentikan bullying (Entenman, Murnen, \& Hendricks, 2005).

Anak-anak yang menjadi korban bullying umumnya memiliki perasaan tidak berdaya, takut dan terancam. Kondisi ini menyebabkan kepercayaan dirinya turun, malu, trauma, tak mampu menyerang balik, merasa sendiri, serba salah, dan takut sekolah (school phobia), dimana ia merasa tidak ada yang menolong. Sedangkan pelaku bullying menjadi tidak mempunyai empati, egois, dan dijauhi teman (Khasanah, 2013). 


\section{DAMPAK BULLYING}

Perilaku bullying yang terjadi seringkali kurang mendapat perhatian yang lebih dari orang tua dan guru, sehingga dampak yang terjadi pada korban maupun pelaku terlambat untuk diketahui oleh lingkungan sekitar. Dalam kasus ini, bullying menimbukan efek yang negatif, yaitu munculnya masalah kecemasan, depresi, dan mengalami penurunan kemampuan belajar karena ia mengalami kesulitan untuk berkonsentrasi dan penurunan dalam ingatannya sehingga prestasi anak secara akademis akan menurun secara signifikan (Hidayati, 2012). Terkadang, korban bullying mengalami depresi yang ekstrim sehingga ia memutuskan untuk melakukan upaya bunuh diri. Anak-anak yang mengalami bullying, mungkin terlihat mampu mengatasi dampak bullying yang terjadi pada dirinya. Tetapi sebenarnya mungkin mereka masih bergulat dengan inner distress dalam diri mereka. Anakanak dengan pengalaman semacam ini apabila tidak memperoleh bantuan dan penanganan yang semestinya akan berkembang menjadi anak yang secara perilaku nampak kuat dan normal namun pada saat bersamaan secara psikologis ia seorang anak yang rentan.

\section{ANAK USIA DINI}

Di Indonesia, yang dikatakan sebagai Anak Usia Dini (AUD) adalah anak yang berusia 0-6 tahun. Pada usia itu, anak mulai mengalami masa tumbuh dan kembang dengan seluruh potensi yang ada di dalam dirinya. Beberapa ahli dalam bidang pendidikan dan psikologi memandang periode usia dini merupakan periode yang penting yang perlu mendapat penanganan sedini mungkin. Periode emas anak disebut sebagai masa keemasan atau the golden ages. Sebab, pada masa itu otak anak sedang mengalami pertumbuhan dan perkembangan yang sangat pesat. Dan, otak merupakan kunci utama bagi pembentukan kecerdasan anak. Periode ini dimulai sejak janin dalam kandungan hingga usia 6 (enam) tahun.

\section{PEMBAHASAN}

Bullying merupakan perilaku yang berbahaya karena dapat memberikan dampak traumatik yang dapat mempengaruhi perilaku anak-anak pada tahap perkembangan selanjutnya, baik pada pelaku bullying, maupun pada korban bullying. Anak yang diusia dininya terindikasi dan terlibat dalam perilaku bullying, berpotensi untuk menjadi pelaku kenakalan di usia remajanya, tindakan kekerasan, serta terjebak dalam tindakan criminal. Pelaku dan korban bullying akan kesulitan untuk melakukan hubungan dengan sosialnya (Surilena, 2016). Sebanyak 57\% orang yang pernah mengalami bullying di usia kanak-kanak 
saat mereka dewasa akan menalami depresi, mempunyai self-esteem yang rendah, dan kesulitan interpersonal.

Salah satu penyebab terjadinya bullying adalah iklim sekolah yang tidak kondusif. Sekolah seharusnya menjadi tempat bagi anak menimba ilmu serta membantu membentuk karakter pribadi yang positif, ternyata menjadi tempat praktik perilaku bullying (Surilena, 2016). Guru memiliki peranan yang sangat besar dalam dinamika kelas. Sebagai pihak yang dinilai memiliki otoritas atas jalannya suatu kegiatan belajar, guru dituntut untuk dapat menciptakan iklim kelas yang sejuk dan memungkinkan interaksi yang sehat antar komponen kelas yang ditandai dengan penghargaan dan kesadaran akan perbedaan tiap-tiap siswa di kelas. Kurangnya pengawasan orang dewasa atau guru pada saat jam istirahat, ketidak pedulian guru dan siswa terhadap perilaku bullying, serta penerapan peraturan anti bullying yang tidak konsisten merupakan kondisi-kondisi yang menumbuh suburkan terjadinya bullying di sekolah (Sitasari, 2016).

Bullying seringkali terjadi di sekolah yang kurang memiliki pengawasan, longgar dalam menerapkan aturan serta pihak-pihak pemegang otoritas tidak memiliki sikap dan pandangan yang tegas terhadap bullying (Elliot, 2008). Disamping itu, jumlah siswa yang terlalu banyak dalam satu kelas juga dapat memicu timbulnya bullying di kalangan siswa (Elliot, 2008). Walaupun tidak ada peraturan yang mengharuskan sekolah mempunyai kebijakan proram anti bullying, akan tetapidalam undang-undang perlindungan anak No. 23 Tahun 2002 pasal 54 yang menyatakan bahwa: "Anak di dalam dan di lingkungan sekolah wajib dilindungi dari tindakan kekerasan yang dilakukan oleh guru, pengelola sekolah atau teman-temannya di dalam sekolah yang bersangkutan, atau lembaga pendidikan lainnya". Hal tersebut menunjukkan bahwa lingkungan sekolah mempunyai kontribusi dalam membentuk kepribadian dan karakter anak.

Komitmen guru di sekolah menjadi faktor yang menentukan dalam penurunan kasus bullying (Arumsari \& Adiyanti, 2013). Pengetahuan yang dimiliki oleh guru TK tentang bullying juga dirasakan masih terbatas. Para guru sering mendengar dan membaca kasus yang terkait dengan perilaku bullying melalui media. Akan tetapi, para guru belum menyadari apakah mungkin di sekitar anak di lingkungan sekolah juga berisiko terjadi bullying, atau bahkan ada anak-anak yang membutuhkan bimbingan karena tampaknya sering menyakiti temannya yang lain (Putri, 2016). Semakin guru memahami dan memiliki keterampilan maka penanganannya menjadi lebih intensif (Horne, Newman, \& Bartolomucci, 2004).

Adanya kesenjangan pengetahuan dan keterampilan guru dalam menangani bullying, maka diperlukan usaha untuk meningkatkannya. Peningkatan pengetahuan dan keterampilan 
guru dapat dilakukan dengan program psikoedukasi (Arumsari \& Adiyanti, 2013).

Psikoedukasi pada guru tentang penanganan bullying di sekolah sangat perlu dilakukan. Oleh karena itu, guru perlu dilatih untuk mengetahui perilaku bullying secara peka dan konsisten (Siswati \& Widayanti, 2009), agar guru dapat mengidentifikasi dan menanggapi perilaku bullying dengan benar. Psikoedukasi yang diberikan pada guru akan menjadi bagian penting dalam program anti-bullying yang ada di sekolah. Dengan pemberian psikoedukasi mengenai bullying kepada guru, guru mulai mengetahui perihal bullying, mampu tidak menggunakan hukuman dalam menyelesaikan masalah bullying ini, dan mulai mampu meningkatkan empati pelaku dan bystander untuk korban (Arumsari \& Adiyanti, 2013).

\section{DAFTAR PUSTAKA}

Arumsari, A.D., \& Adiyanti, P.M.G. (2013). Meningkatkan Keterampilan Guru Menangani Bullying: Metode Support Group. (etd.repository.ugm.ac.id).

Cassidy, Toni. (2009). Bullying and victimization in school children: the role of social identity, problem-solving style, and family and school context. Soc Psychol Educ (2009) 12:6376.

Elliot, Michele (ed). (2008). Bullying, A Practical uide to Coping for Schols, 3rd Edition. London: Pearson Education in Association with Kidscape.

Entenman, J., Murnen, T. J., \& Hendricks, C. (2005). Victims, Bullies, and Bystanders in K-3 Literature. International Reading Association (pp. 352-364).

Khasanah, Iswatun. (2013). Program "SAHABAT" Sebagai Salah Satu Program Alternatif Penanganan Bullying pada Anak Usia Dini. Jurnal Pendidikan Anak, vol. II, Edisi 2, bulan Desember.

Horne, M. A., Bartolomucci, C. L., \& Carlson, D. N. (2004). Elementary School Bully Buster Program: Understanding Why Children Bullying and What To Do About It. In A. Espelage, D. L., B. Swearer, S. M (Eds). Bullying in America Schools: A Social Ecological Perspective on Pervention and Intervention (pp. 297-325). London: Laurence Erlbaum Associates.

Newman-Carlson, D., \& Horne, M. A. (2004). Bully Buster: A Psychoeducational Intervention for Reducing Bullying Behavior in Middle School Students. Journal of Counseling Development, 83 (2), 259-265.

Olweus, D. (1997). Bully / Victim Problems in School: Facts and Intervention. European Journal of Psychology of Education, XII (4), 495-510. 
Olweus, D. (2005). Bullying at School: What We Know and What We Can Do. Australia: Blackwell Publishing.

Porter, L. (2007). Student Behavior: Theory and Practice for Teachers, $3^{\text {rd }}$ Ed. Sydney: Allen and Uwin.

Putri, Dewi Arum Widhiyanti Metra. (2016). Media Anti Bullying: Pembimbingan Anak Usia Dini pada Taman Kanak di Kota Singaraja. P-ISSN: 1410-4369, Vol 5, No 1, bulan Januari.

Rigby, Ken. (2003). Addressing Bullying in Schools: Theory and Practice. iAustralian Institute of Criminology, June, No. 259

Robinson, G., \& Maines, B. (2008). Bullying: A Complete Guide to The Support Group Method. London: Sage Publication Ltd.

Siswati, \& Widayanti, C. G. (2009). Fenomena Bullying di Sekolah Dasar di Semarang: Sebuah Studi Deskriptif. Jurnal Psikologi Undip, 5 (2).

Sitasari, Novenda Wahyu. (2016). Pengetahuan dan Keterampilan Guru dalam Menangani Perilaku Bullying. Forum Ilmiah, Vol 13, Nomer 2, bulan Mei.

Smith, J. D., Cousins, J. B., \& Stewart, R. (2005). Antibullying Interventions in Schools: Ingredients of Effective Programs. Canadian Journal of Education, 28 (4), 739-762.

Sullivan, K. (2000). School Bullying: Issues For Teachers. Issue, 23, 1-7.

Surilena. (2016). Perilaku Bullying (Perundungan) pada Anak dan Remaja. CDK-236, Vol 43 No 1.

The British Columbia Safe School Centre. (1999). Fokus on Bullying: A Prevention Program for Elementary School Communities. 